Sciences

Vol. 06, No. 01, pp. 62-74 March 2013

\title{
A NOVEL METHOD FOR TUNING PID CONTROLLER
}

\author{
Abidaoun H. shallal ${ }^{1}$, Rawaa A. Karim ${ }^{2}$, Osama Y. Al-Rawi ${ }^{3}$ \\ ${ }^{1}$ Engineering Collage, Diyala University, ${ }^{2,3}$ Al-Khwarizmy Engineering College, Baghdad \\ University \\ (Received:24/4/2012; Accepted:22/5/2012)
}

\begin{abstract}
Proportional integral derivative (PID) control is the most commonly used control algorithm in the industry today. PID controller popularity can be attributed to the controller's effectiveness in a wide range of operation conditions, its functional simplicity, and the ease with which engineers can implement it using current computer technology.

In this paper,the Dc servomotor model is chosen according to his good electrical and mechanical performances more than other Dc motor models, discuss the novel method for tuning PID controller and comparison with Ziegler - Nichols method from through parameters of transient response of any system which uses PID compensator .
\end{abstract}

Keywords:- PID tuning, Comparison.

\section{INTRODUCTION}

PID controllers have been widely used in industries for various applications and it plays a vital role in automation. It has been a crucial problem to tune properly the gains of the PID controller because many industrial plants are often burdened with the characteristics such as higher order, time delay and nonlinearities ${ }^{(1)}$. While modeling the complex systems like aircraft mechanism, Atomic plant process monitoring, fuel injector and spark timing of auto mobiles it can be noted that the system order is increased. The analysis and synthesis of higher order systems are difficult and generally not desirable on economic and computati- onal considerations. Thus, it is necessary to obtain a lower order system so that the obtained lower order maintains the characteristics of the original system. This helps in minimizing the variations during design and realization of suitable control system components to be attached to the original system.

Model order formulation is the process of deriving the lower order model from the higher order model. Model order formulation approximates the complex form system 
by simple one. The main aim of the formulation is to find the best possible approximation of the output of the original system. During the past four decades, numerous impressive varieties of new techniques (2) - (6) have been developed for obtaining lower order models from higher order linear system. Each of these methods has both advantages and disadvantages when tried on a particular system.

The purpose of developing a control system is to enable stable and reliable control. Once the control system has been specified and the type of control has been decided, then the design and analysis are done. There are three major objectives of system analysis and design: producing the desired transient response, reducing steady-state error ,and achieving stability ${ }^{(7)}$.

Several methods have been developed for designing a PID controller. Ziegler et al ., (8) have proposed the frequency response method by using information from the Nyquist curve of the system. The method is only suitable for systems with mono- tonic step response. Hang et al., (9) have reexamined the Ziegler-Nichols method and proposed new tuning formulae, in which setting point weight for systems with PID controllers are introduced. Zhuang et al., ${ }^{(10)}$ proposed an optimal design of PID controllers based on the minimization of an integral criterion. Yeung et al., ${ }^{(11)}$ presented the graphical method for common continuous time and discrete time compensators. The main purpose of the approach is to reduce the excessive overshoot of the system to be compensated. To enhance the capabi- lities of traditional PID parameter tuning techniques, several intelligent approaches have been suggested to improve the PID tuning, such as those using Genetic Algorithms (GA) ${ }^{(12)}$ and the Particle Swarm Optimization (PSO) ${ }^{(13)}$.With the advance of computational

methods in the recent times, optimization algorithms are often proposed to tune the control parameters in order to find an optimal performance ${ }^{(14)}$.

In 1942 Ziegler and Nichols, both employees of Taylor Instruments , described simple mathematical procedures, the first and second methods respectively, for tuning PID controllers. These procedures are now accepted as standard in control systems practice. Both techniques make a priori assumptions on the system model, but do not require that these models be specifically known. Ziegler-Nichols formulae for specifying the controllers are based on plant step responses. Tuning rules based on a measured step response are also called process reaction curve methods. 
The novel method for tuning PID controller has been employed successfully to find the values of PID parameters. Generally, the novel method is characterized as a simple concept, easy to implement, and computationally efficient .

In this paper a novel method is proposed to design a PID controller for Dc motor speed . matlab programming procedures are used to obtain the optimal response for Dc motor with PID controller . The novel method for tuning PID controller is compared with Ziegler Nichols first method.

\section{PID CONTROLLER METHOD}

The standard block diagram of PID controller is shown in figure (1) . PID controller can be mathematically represented as ${ }^{(15)}$,

$u(t)=K_{p}\left[e(t)+\frac{1}{T_{i}} \int_{0}^{z} e(\tau) d \tau+T_{d} \frac{d e(t)}{d t}\right]$

Where $u(t)$ and $e(t)$ denotes the control and error signals of the system. $K_{p}$ is the proportion gain , $T i$ and $T d$ represents the integral and derivative time constants respectively. The

corresponding PID controller transfer function $G_{c}(s)$ is given as,

$G_{c}(s)=K_{p}\left(1+\frac{1}{T_{i} s}+T_{d} s\right)$

Equations (2) can be rewritten as ,

$G_{q}(s)=K_{p}+\frac{K_{i}}{s}+K_{D} S$

$K_{i}$ and $K_{d}$ are represents the integral and derivative gain values of the controller.

\section{ZIEGLER - NICHOLS FIRST METHOD}

The Ziegler - Nichols rules for tuning PID controller have been very influential ${ }^{(8)}$.The rules do ,however, have severe drawbacks, they use insufficient process information and the design criterion gives closed loop systems with poor robustness ${ }^{(16)}$.

Ziegler and Nichols presented two methods, a step response method and a frequency response method.

The first method is applied to plants with step responses of the form displayed in figure (2). This type of response is typical of a first order system with transportation delay, such as that induced by fluid flow from a tank along a pipe line. 
It is also typical of a plant made up of a series of first order systems. The response is characterized by two parameters, $L$ the delay time and $T$ the time constant. These are found by drawing a tangent to the step response at its point of inflection and noting its intersections with the time axis and the steady state value. The plant mode 1 is therefore

$G(s)=\frac{K e^{-s L}}{T s+1}$

Ziegler and Nichols derived the following control parameters based on this model

where

$T_{i}=K_{i} / K_{p} \quad$ and $\quad T_{d}=K_{d} / K_{p}$

Transfer function of PID controller tuned using the first method

$$
\begin{aligned}
G_{o}(s) & =K_{p}\left(1+\frac{1}{T_{i} s}+T_{d} s\right) \\
& =1.2 \frac{T}{L}\left(1+\frac{1}{2 L s}+0.5 L s\right) \\
& =0.6 T \frac{\left(s+\frac{1}{L}\right)^{2}}{s}
\end{aligned}
$$

It should be noted that the response curve of figure (2) is also typical of over damped second order systems. Other process reaction curve tuning rules are also described, sometimes in graphical form, to control delayed processes represented by a variety of models (17) .The advantage of process reaction curve tuning strategies is that only a single experimental test is necessary. However, the disadvantages of the strategy are primarily based on the difficulty, in practice, of obtaining an accurate process model; for example, load changes may occur during the test which may distort the test results and a large step input may be necessary to achieve a good signal to noise ratio. Similar disadvantages arise in any tuning method dependent on prior model development.

\section{THE NOVEL METHOD FOR TUNING PID CONTROLLER}

If the transfer function for the second order as shown

$$
G(s)=\frac{k}{(s+a)(a+b)}
$$


where the poles $\mathrm{a}$ and $\mathrm{b}$ are different and greater than zero.The PID controller for the following structure

$$
\begin{aligned}
& \mathrm{G}_{\mathrm{g}}(\mathrm{s})=\mathrm{K}_{\mathrm{p}}+\frac{\mathrm{K}_{\mathrm{i}}}{\mathrm{s}}+\mathrm{K}_{\mathrm{d}} \mathrm{s}
\end{aligned}
$$

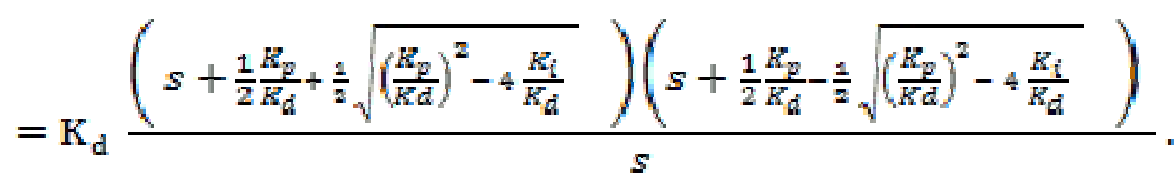

Through form the structure for the PID controller, see that when added the value of gain $K_{d}$ and two zeros in the different position; assume that one pole in the origin point and through the following equations, get the parameters for the PID controller. In equation (9) let as consider the value of gain will be added to the system is $\frac{a}{4}$; through that from trial and error method.

$K_{d}=\frac{a}{4}$

In equation (10) put the first zero in the pole that near from origin position .

$\frac{2}{2} \frac{K_{Q}}{K_{d}}+\frac{1}{2} \sqrt{\left(\frac{K_{Q}}{K d}\right)^{2}-4 \frac{K_{i}}{K_{d}}}=a$

In equation (11) put the second zero in middle distance between the poles, solve these equations (10) \& (11) to get $K_{p} \& K_{i}$ as a function of (b \& a) .

$\frac{1}{2} \frac{K_{p}}{K_{d i}}-\frac{1}{2} \sqrt{\left(\frac{K_{p}}{K_{d}}\right)^{2}-4 \frac{K_{i}}{K_{d i}}}=\frac{1}{2}(b-a)$

$\frac{K_{p}}{K_{d}}=a+\frac{1}{2}(b-a) \ldots \ldots$
substituting equation (9) in
$K_{p}=\frac{a}{4}\left[a+\frac{1}{2}(b-a)\right]$.

substituting equations (13) \& (9) in equation (10), get the following equation

$\frac{1}{2}\left[a+\frac{1}{2}(b-a)\right]+\frac{1}{2} \sqrt{\left(a+\frac{1}{2}(b-a)\right)^{2}-4 \frac{k_{i}}{a / 4}}=a$

After solve equation (14), get the value of $K_{i}$.

$K_{i}=\frac{a^{2}}{8}(b-a)$

substituting equations (13) \& (9) in equation (10), get the following equation

$$
K_{i}=\frac{a}{8}(b-a)
$$




\subsection{Model of dc motor}

DC machines are characterized by their versatility. By means of various combinations of shunt, series, and separately -excited field windings they can be designed to display a wide variety of volt-ampere or speed-torque characteristics for both dynamic and steady-state operation. Because of the ease with which they can be controlled systems of Dc machines have been frequently used in many applications requiring a wide range of motor speeds and a precise output motor control ${ }^{(18,19)}$. Figure (3) show the equivalent circuit of Dc servomotor. The parameters of an actual Dc servomotor used in this paper are listed in table (1) and the transfer function for this Dc motor is ${ }^{(20)}$ :

$$
G(s)=\frac{0.0147}{0.000007242 s^{2}+0.000207 s+0.000437}
$$

\section{RESULTS AND DISCUSSIONS}

In this paper, a PID controllers used Ziegler - Nichols first method to find the suitable parameters of Dc motor speed control system. The structure of a PID controller as shown in figure (4).

$e(t)=r(t)-y(t)$

At first applying Ziegler - Nichols first method on the open loop step response for Dc motor to choose a suitable parameters of PID controller, and get $\mathrm{T}=0.55 \& \mathrm{~L}=0.05$; from table (2) get the values of $K_{p}=13.2, K_{i}=132 \& K_{d}=0.33$. The speed response of PID controller tuning parameters using Ziegler-Nichols is shown in figure (5). Table( 3) lists the results of PID controller by using the Ziegler - Nichols method.After that the PID controller parameters are find by novel method; from equation (16) let as consider the values of $a=2.2954 \& b=26.2878$, after substituting these values in equations (9 , $13 \& 15$ ) get the values of $K_{p}=8.20123, K_{i}=15.801578 \& K_{d}=0.57385$. The speed response of PID controller tuning parameters using novel method is shown in figure (6). Table (4) lists the results of PID controller by using the novel method for tuning PID controller .

\section{CONCLUSIONS}

There are many motor control system design methods that may be more or less appropriate to a specific type application. The design of PID controller parameters 
using two methods, Ziegler - Nichols first method and the novel method. From the results that find by matlab programming V. 7.10 and explaining in table ( $3 \& 4)$, the novel method is better than Ziegler - Nichols first method.The PID controller parameters using novel method is the best which presented satisfactory performances and possesses good robustness ( no overshoot, minimal settling time \& steady state error equal to zero ).

\section{REFERENCES}

1. G. J. Silva, A. Datta , 2002 , “New results on the synthesis of PID controllers", IEEE Transactions on Automatic Control, Vol. 47, No. 2, pp. 241-252.

2. C. F. Chen and L. S. Shien , 1968, "A novel approach to linear model simplification”, International Journal of Control System, Vol. 8 , pp. 561-570 .

3. V . Zaliin, 1973 , "Simplification of linear time - invariant system by moment approximation", International Journal of Control System, Vol. 1, No. 8 , pp. $455-460$.

4. P. O. Gutman, C. F. Mannerfelt and P. Molander, 1982 , "Contributions to the model reduction problem", IEEE Trans. Auto. Control, Vol. 27, pp. 454-455.

5. R. Prasad and J. Pal, October, 1991, "Stable reduction of linear systems by continued fractions", Journal of Institution of Engineers IE(I) Journal, Vol. 72, pp. 113-116.

6. S. Mukherjee, Satakshi and R. C. Mittal, 2005, "Model order reduction using response- matching technique”, Journal of Franklin Inst., Vol. 342 , pp.503-519.

7. J. J. Jordan, Oct. 2001 , “A DC Motor Drive for a Dyno - Microcontroller and Power Electronic ", University of Queensland, Australia, BSc. thesis.

8. J. G. Ziegler, N. B. Nichols, 1942 , “Optimum settings for automatic controllers ", Transaction of the AMSE, Vol. 64 , pp. 759-768.

9. C. C. Hang, K. J. Astrom and W. K. Ho,1991, "Refinements of the Ziegler- Nichols tuning formula", IEEE Proceedings of Control Theory and Applications, Vol. 138, No. 2, pp.111-118.

10. M. Zhuang, D. P. Atherton,1993, “Automatic tuning of optimum PID controllers", IEEE Proceedings of Control Theory and Applications, Vol. 140, No. 3, pp. 216-224. 
11. K. S. Yeung, K. Q. Chaid and D. X. Tien,1995, “Bode design charts for continuous- time and discrete- time compensators", IEEE Transactionon Education", Vol. 38, No. 3, pp. 252-257.

12. A.Varsek, T. Urbacic and B. Filipic,1993,"Genetic Algorithms in Controller Design and Tuning”, IEEE Transaction on Sys. Man and Cyber, Vol. 23, No.5, pp.1330-1339.

13. Z. L. Gaing,2004, “A particle swarm optimization approach for optimum design of PIDcontroller in AVR system", IEEE Transaction on Energy Conversion, Vol.19, No.2, pp.384-391.

14. J. Zhao, T. Li, J. Qian, 2005 , “Application of particle swarm optimization algorithm on robust PID controller tuning ", Advances in Natural Computation - Springer , pp.948- 957.

15. M. Gopal , 1997, "Control systems principle and design”, Tata McGraw Hill Publications, New Delhi .

16. Astrom K.J., Hagglund T. , 2001.“ The future of PID control” , Control Engineering Practice 9,pp. 1163-1175.

17. A. O'Dw yer, 2006, Handbook of PI and PID controller tuning rules (Edition 2).London, U.K.: to be published by Imperial College Press .

18. Halila A., May 2001, "Étude des machines à courant continu”, MS Thesis, University of LAVAL, (in French) .

19. Capolino G.A., Cirrincione G., Cirrincione M., Henao H., Grisel R., June 2001, “Digital Signal Processing for Electrical Machines”, Invited paper, Proceedings of ACEMP'01(Aegan International Conference on Electrical Machines and Power Electronics),Kusadasi, Turkey, pp. $211-219$.

20. M . B .B .Sharifian, R .Rahnavard and H . Delavari ., April 2009 , “Velocity Control of Dc Motor Based Intelligent methods and Optimal Integral State Feedback Controller" , International Journal of Computer Theory and Engineering, Vol. 1 , No. 1, pp. $81-84$. 


\section{LIST OF SYMBOLS}

\begin{tabular}{||c|l||}
\hline \hline $\mathrm{E}$ & Error \\
\hline $\mathrm{L}$ & Delay time \\
\hline $\mathrm{T}$ & Delay constant \\
\hline $\mathrm{y}(\mathrm{t})$ & Dc motor velocity (step response) \\
\hline $\mathrm{u}(\mathrm{t})$ & Dc motor input \\
\hline $\mathrm{r}(\mathrm{t})$ & Reference input (step function) \\
\hline $\mathrm{e}(\mathrm{t})$ & Error between Dc motor velocity and reference input \\
\hline \hline
\end{tabular}

\section{LIST OF ABBREVIATIONS}

\begin{tabular}{||c|l||}
\hline \hline $\mathrm{P}$ & Proportional \\
\hline $\mathrm{I}$ & Integral \\
\hline $\mathrm{D}$ & Derivative \\
\hline PID & Proportional - Integral - Derivative \\
\hline$K_{p}$ & Proportional gain \\
\hline$K_{i}$ & Integral gain \\
\hline$K_{\mathrm{d}}$ & Derivative gain \\
\hline$T_{\mathrm{d}}$ & Derivative time \\
\hline$T_{\mathrm{i}}$ & Integral time \\
\hline
\end{tabular}

Table (1) : Dc Servomotor Parameters.

\begin{tabular}{|c|c|}
\hline$R_{\mathrm{a}}$ & $4.67 \Omega$ \\
\hline$L_{\mathrm{a}}$ & $170 \times 10^{-3} \mathrm{H}$ \\
\hline$J$ & $42.6 \times 10^{-6} \mathrm{Kg} \cdot \mathrm{m}^{2}$ \\
\hline$f$ & $47.3 \times 10^{-6} \mathrm{~N} \cdot \mathrm{m} / \mathrm{rad} / \mathrm{sec}$ \\
\hline$K$ & $14.7 \times 10^{-3} \mathrm{~N} . \mathrm{m} / \mathrm{A}$ \\
\hline$K_{\mathrm{b}}$ & $14.7 \times 10^{-3} \mathrm{~V} \cdot \mathrm{sec} / \mathrm{rad}$ \\
\hline
\end{tabular}

Table (2) : Ziegler - Nichols Recipe - First Method.

\begin{tabular}{|c|c|c|c|}
\hline $\begin{array}{c}\text { Type of } \\
\text { controller }\end{array}$ & $K_{p}$ & $T i$ & $T d$ \\
\hline P & $\frac{T}{L}$ & $\infty$ & 0 \\
\hline PI & $0.9 \frac{T}{L}$ & $\frac{L}{0.3}$ & 0 \\
\hline PID & $1.2 \frac{T}{L}$ & $2 L$ & $0.5 L$ \\
\hline
\end{tabular}


Table (3) : Results of PID controller using Ziegler - Nichols first method.

\begin{tabular}{|c|c|}
\hline$\left[\mathrm{K}_{\mathrm{p}} ; \mathrm{K}_{\mathrm{i}} ; \mathrm{K}_{\mathrm{d}}\right]$ & {$[13.2 ; 132 ; 0.33]$} \\
\hline Settling time $(\mathrm{sec})$ & 0.00504 \\
\hline Overshoot $(\%)$ & 1.54 \\
\hline Steady state error & 0 \\
\hline
\end{tabular}

Table (4) : Results of PID controller using Novel method.

\begin{tabular}{|c|c|}
\hline$\left[\mathrm{K}_{\mathrm{p}} ; \mathrm{K}_{\mathrm{i}} ; \mathrm{K}_{\mathrm{d}}\right]$ & {$[8.20123 ; 15.801578 ; 0.57385]$} \\
\hline Settling time $(\mathrm{sec})$ & 0.00406 \\
\hline Overshoot $(\%)$ & 0 \\
\hline Steady state error & 0 \\
\hline
\end{tabular}

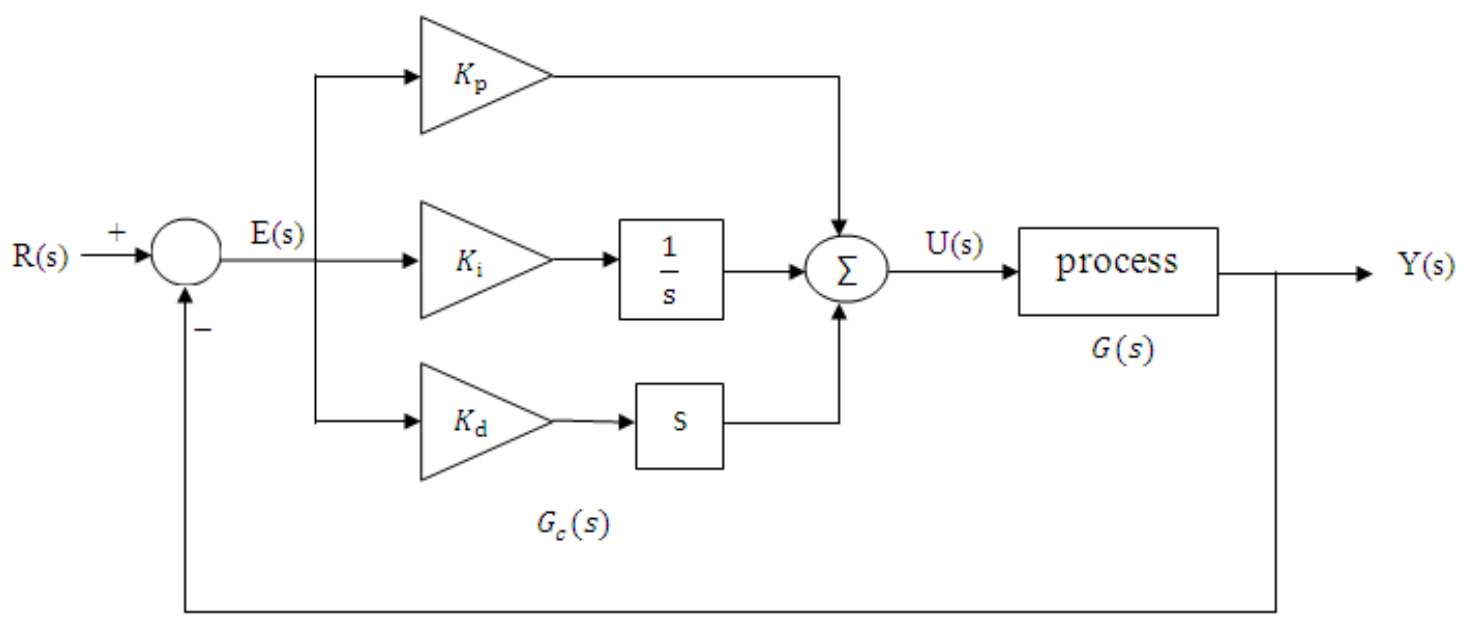

Fig.(1) : General block diagram of PID controller. 


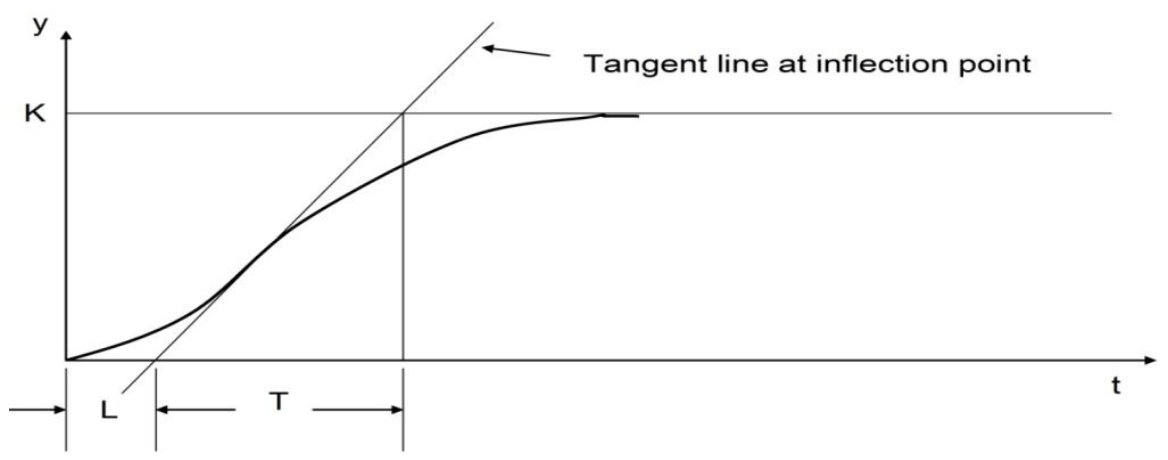

Fig. (2): Response Curve for Ziegler-Nichols First Method.

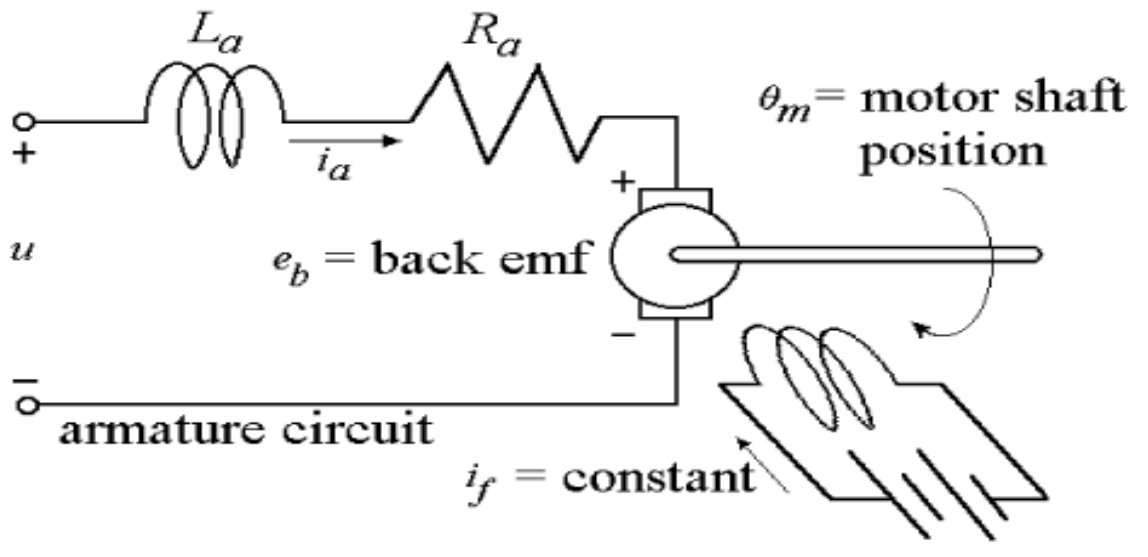

\section{field circuit}

Fig. (3) : Equivalent circuit of Dc servomotor.

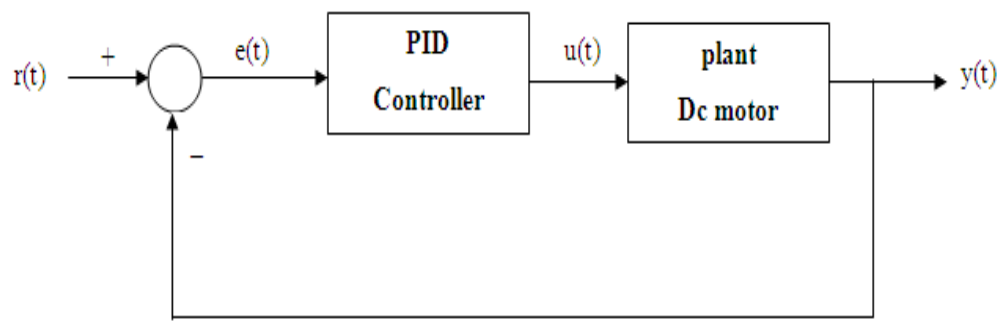

Fig. (4) : A Typical PID controller system. 


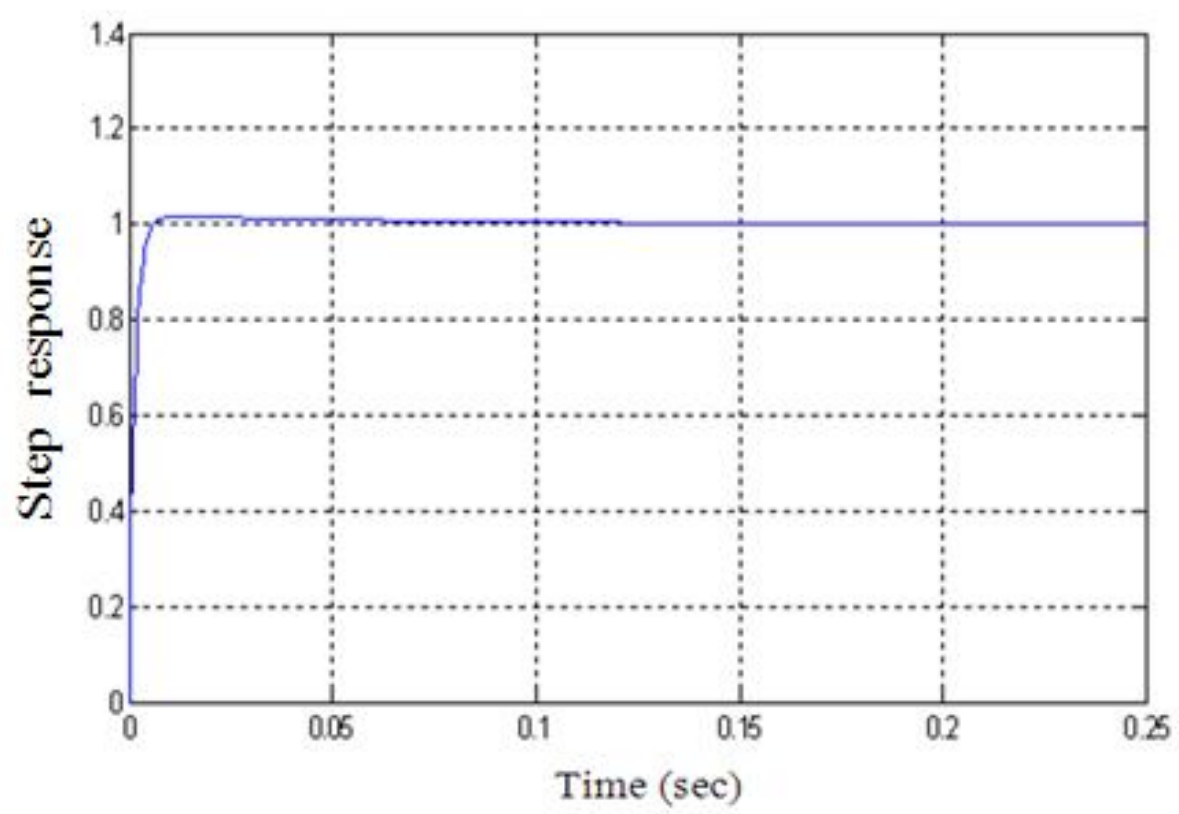

Fig.(5) : The step response of the PID controller tuning parameters using Ziegler - Nichols first method.

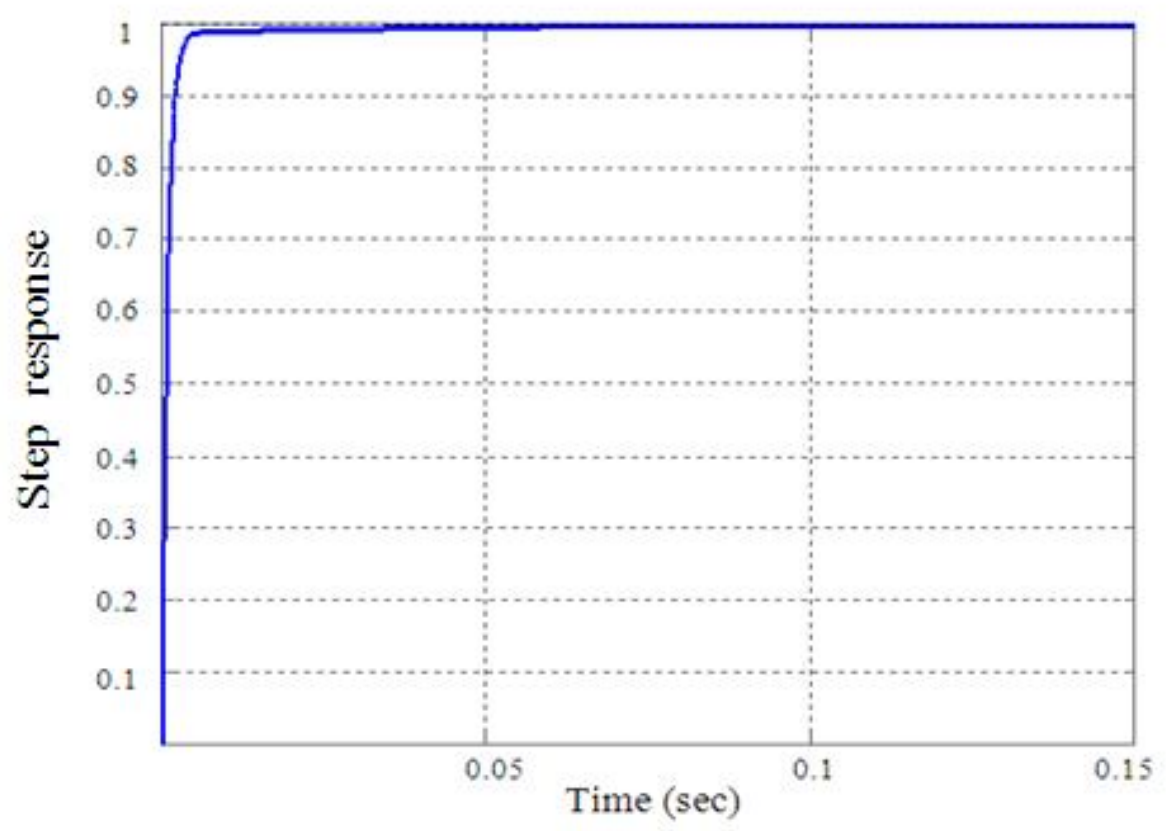

Fig.(6) : The step response of the PID controller tuning parameters using Novel method. 


\section{PID طريقة مبتكرة لضبط جهاز السيطرة}

$$
\begin{aligned}
& \text { اسامة ياسين الراوي } \\
& \text { مدرس دكتور } \\
& \text { كلية هندسة الخوارزمي دني } \\
& \text { جامعة بغداد }
\end{aligned}
$$

$$
\text { كلية الهندسة - مهاء عامر كريم }
$$

$$
\begin{gathered}
\text { كبدعون حمدان شلال مدرس مساعد الهندسة_جامعة ديالى } \\
\text { كلية }
\end{gathered}
$$

الخلاصة

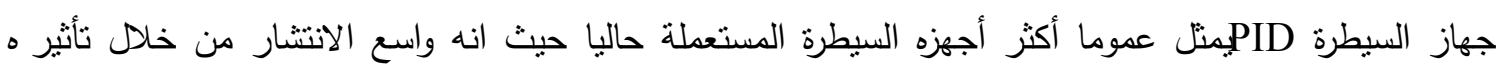
الكبير على معظم الأنظمة الواسعة وذلك لسهولته في التطبيق من قبل المهندسين وبساطته الوظيفية والذي يمكن استعماله

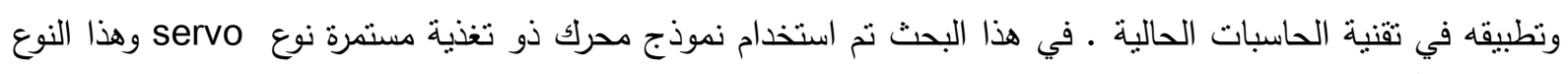
افضل اداءً من الناحية الكهربائية والميكانيكية مع بقية نماذج المحركات ذات التئية التغذية المستمرة ، وتم مناقثنة الطريقة

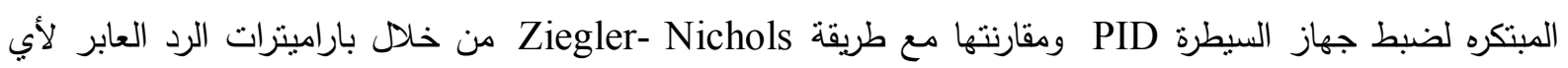

ن PID نظام بستعمل جهاز السيطرة الكلمات الدالة : ضبط PID ، مقارنة. 